Journal of Engineering and Applied Sciences 15 (7): 1724-1727, 2020

ISSN: 1816-949X

(C) Medwell Journals, 2020

\title{
Maritime Weather Predictor Design Based Neural Network and ANFIS to an Increase in Accuracy in the Java Sea
}

\author{
${ }^{1}$ Wimala L. Dhanistha, ${ }^{1}$ Wisnu Wardhana and ${ }^{2}$ Mufidatul Islamiyah \\ ${ }^{1}$ Department Ocean of Engineering, Institut Teknologi Sepuluh Nopember, Surabaya, Indonesia \\ ${ }^{2}$ Asia Malang Institute of Technology and Business, Malang, Indonesia
}

\begin{abstract}
Sea transportation is a mainstay transportation in Indonesia, it is because Indonesia consists of thousands of islands, so that, to connect between islands, sea transportation is needed. Waves are very closely related to the sea, waves that are negative that is waves that can endanger shipping. One of the factors causing sea accidents is natural disasters, namely high waves. To minimize accidents due to high waves, wave predictions can be made in the hours to come using the neural network algorithm. Neural network was chosen because of its advantages in processing system input-output data even though the system is nonlinear. The advantage is that the neural network is chosen as a wave height predictor algorithm. ANFIS is an algorithm for the development of a combination of neural networks and fuzzy artificial intelligence. The ability of ANFIS to predict wave heights is no less good with neural networks, it is because ANFIS is a combination of neural network and fuzzy. It is hoped that by doing this research it can compare which algorithm is better in predicting wave heights.
\end{abstract}

Key words: Wave height, wind speed, neural network, ANFIS, algorithm

\section{INTRODUCTION}

Indonesia is known as an archipelago because it has thousands of islands. So, no wonder sea transportation is used as transportation that is considered important in inter-island trade or transportation. The smooth sea transportation is very much influenced by maritime weather which is wave. Waves can sink ships and can increase the level of accidents in sea transportation, so, wave height is important in sea transportation. Surabaya-Banjarmasin shipping lane is a path that has a high enough potential for accidents in Indonesian waters. Factors that can cause accidents in sea transportation that occur include $41 \%$ human error, $38 \%$ force majeure and $21 \%$ due to ship structure.

Neural Network (NN) is one of the Artificial Intelligence (AI) algorithms or commonly called artificial intelligence that the concept of the neural network system in the human body. Neural network is a mathematical structure with easy process elements or nodes, neural network is an efficient method for complex input-output relationships. Another opinion says that neural network is a process of distribution of parallel information and is able to process nonlinear systems well (Paras et al., 2007). Previous studies using neural network algorithm to predict rainfall (RF) and humidity $(\mathrm{RH})$ by using minimum-maximum temperature, rainfall and humidity data (Paras et al., 2007), neural network algorithm can predict better than the NLARX algorithm, predicted wave heights using neural networks and compared them with the regression method, predicted wave heights and wind speeds with 3 input variations and predicted wave heights with intervals of 12 and $24 \mathrm{~h}, 5$ and 10 days (Makarynskyy et al., 2004). Wave height prediction using backpropagation methods on neural networks produces accurate predictions with low error rates. Algorithm design is more accurate at one point or cannot be used at different locations (Dhanistha et al., 2017, 2018a, b). In addition to using neural networks to predict wave heights, it can also use machine learning. ANFIS is the development of artificial intelligence which is a combination of neural network algorithm and fuzzy algorithm. Prediction of wave heights has been carried out in Java sea.

Neural network: Neural Network (NN) can be used to predict wave heights at a later time. The advantage of this Artificial Neural Network (ANN) is having a black box that can learn the nature of the input and output that we enter. The results obtained from this ANN are in the form of weights which are then used to predict wave heights. Artificial neural networks begin with scaling or scaling data that is manned to equalize the range of input and output between 0 to 1 . After that determine how much data is used for training and validation. Training is used to study neural networks regarding the relationship between input and output, after which it is tested using validation data. The amount of training data is greater

Corresponding Author: Wimala L. Dhanistha, Department Ocean of Engineering, Institut Teknologi Sepuluh Nopember, Surabaya, Indonesia 
J. Eng. Applied Sci., 15 (7): 1724-1727, 2020

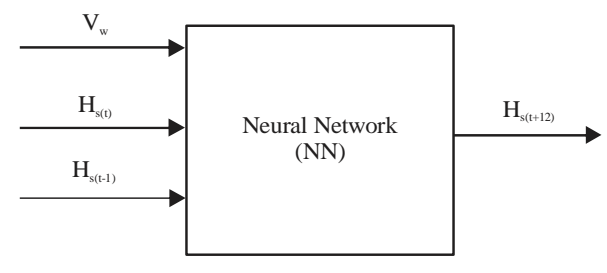

Fig. 1: Block diagram neural network

than validation data which is $80 \%$ of data for training and $20 \%$ of data for validation. The 80:20 ratio will be used in this study because it has been proven that the $80: 20$ ratio has better results than 70:30.

After the distribution of training and validation data, the next step is to choose a network architecture. Network architecture uses many layers or multi-layer perceptron, this network consists of 3 layers, namely the input layer, the hidden layer and the output layer. The choice of multilayer perceptron or many layer networks is because these networks are able to solve more complex problems compared to single layers. This study will use the number of hidden layers in previous studies because at the same location, 7 hidden layers have been used and are able to produce a fairly accurate RMSE (Dhanistha et al., 2017). The 7 hidden layers are used because the results of predictions using fewer hidden layers produce a greater RMSE, so, the accuracy of the predictor is less accurate. Meanwhile, if using a hidden layer with a large amount will result in ups and downs RMSE and only produces very little difference with 7 hidden layer.

Figure 1 is a block diagram, block diagram is used to facilitate the work of input and output used. Input in the form of wind speed at this time $\left(\mathrm{Vw}_{(\mathrm{t})}\right)$, wave height at current $\left(\mathrm{Hs}_{(\mathrm{t})}\right)$ and height of waves in the previous hour $\left(\mathrm{Hs}_{(\mathrm{t}-1)}\right)$. The third input was chosen because the height of the wave is influenced by the wind and the height of the previous wave. Insert variations to predict wave heights have also been made and wind speeds, current wave heights and wave heights in the previous hour produce the smallest RMSE (Makarynsky et al., 2004).

ANFIS: Artificial Neural network Fuzzy Inference System (ANFIS) architecture design consists of 5 layers. The first layer is input in the form of current wind speed $\left(\mathrm{Vw}_{(\mathrm{t})}\right)$, current wave height $\left(\mathrm{Hs}_{(\mathrm{t})}\right)$ and previous wave height $\left(\mathrm{Hs}_{(\mathrm{t}-1)}\right)$. The second layer is the membership function input, the third layer is the rule, the fourth layer is the membership function output and the fifth layer is the system output. The number of membership functions in each input is 4 and produces a good RMSE. In previous studies about wave height prediction, the Gaussian type membership function was used, this is because the Gausian type is a type of membership function

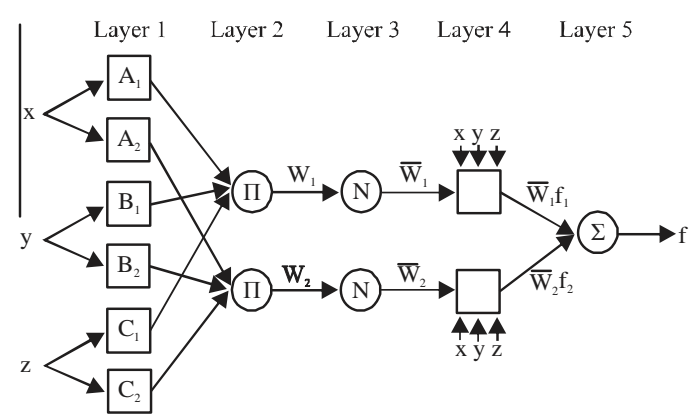

Fig. 2: ANFIS

suitable for nonlinear systems. From these data which will be used as a reference for this research (Fig. 2).

In this study the wave height is caused by wind. The data used are wind speed and wave height data from 2012-2017. The use of wind speed data is because the wave height is influenced by the blowing wind speed. The smaller the wind speed that blows, the lower the wave height that occurs. Conversely, the greater the wind speed that blows, the higher the wave height that occurs. Table 1-3 is a table of wind speeds that occurred in 2012-2017 totaling 46.016 wind speed data.

We can pull out from Table 1 until 3 that wind speed every year the highest average happened between december until january or on rainy season.

Wave height: In addition, to the velocity wind, the waves height is also influenced by the height of waves itself at an earlier time. So that, this research need data the height of waves in 2012-2017 as many as 46.016 data the height of waves in Table 4-6.

Table 4-6 represents data wave level in their one point based on the average of per year and altitudes waves million per year. Equal to wind speed, the maximum waves happened in december-february coincide with rainy season.

Prediction: After conducted training and validation, algorithm JST it produces weights which will used to prediction height waves. A Fig. 3 is a chart prediction height waves each in waters Surabaya (point A), Fig. 4 the Java sea (point B) and Fig. 5 waters banjarmasin (point C). Blue is the height of waves of data BMKG and red is the height of waves the results of a prediction JST based on wind speed, the height of waves now and heights of the waves an hour before.

Root Mean Square Error (RMSE) used to assess the relative the predictions. The less RMSE produced, the more both based on a prediction obtained (Dhanistha et al., 2018a, b). RMSE prediction in point A is 0.04, RMSE prediction in point $\mathrm{B}$ is 0.21 and RMSE prediction in point $C$ is 0.23 . While predictions 
Table 1: Wind speed point A

\begin{tabular}{|c|c|c|c|c|c|c|}
\hline \multirow[b]{2}{*}{ Parameters } & \multicolumn{6}{|l|}{ Years } \\
\hline & 2012 & 2013 & 2014 & 2015 & 2016 & 2017 \\
\hline Average & 3.91 & 3.83 & 4.14 & 3.22 & 4.17 & 6.28 \\
\hline Maximum & 11 & 15 & 13.8 & 16.91 & 10.29 & 14.55 \\
\hline Date & 27 January & 25 December & 5 February & 7 February & 31 December & 10 January \\
\hline
\end{tabular}

Table 2: Wind speed point B

\begin{tabular}{|c|c|c|c|c|c|c|}
\hline \multirow[b]{2}{*}{ Parameters } & \multicolumn{6}{|l|}{ Years } \\
\hline & 2012 & 2013 & 2014 & 2015 & 2016 & 2017 \\
\hline Average & 12.42 & 10.84 & 11.54 & 8.15 & 6.14 & 10.36 \\
\hline Maximum & 25.14 & 27.72 & 24.48 & 22.97 & 15.98 & 25.94 \\
\hline Date & 28 February & 29 December & 18 February & 12 January & 10 February & 15 January \\
\hline
\end{tabular}

Table 3: Wind speed point C

\begin{tabular}{|c|c|c|c|c|c|c|}
\hline \multirow[b]{2}{*}{ Parameters } & \multicolumn{6}{|l|}{ Years } \\
\hline & 2012 & 2013 & 2014 & 2015 & 2016 & 2017 \\
\hline Average & 5.36 & 4.98 & 5.11 & 4.97 & 3.63 & 4.29 \\
\hline Maximum & 11.59 & 13.26 & 10.26 & 11.25 & 10.86 & 12.38 \\
\hline Date & 20 January & 5 January & 10 February & 15 February & 13 January & 9 January \\
\hline
\end{tabular}

Table 4: Wave height point A

\begin{tabular}{|c|c|c|c|c|c|c|}
\hline \multirow[b]{2}{*}{ Parameters } & \multicolumn{6}{|l|}{ Years } \\
\hline & 2012 & 2013 & 2014 & 2015 & 2016 & 2017 \\
\hline Average & 3.92 & 3.82 & 4.14 & 3.78 & 4.09 & 6.08 \\
\hline Maximum & 11.04 & 14.92 & 13.96 & 16.86 & 10.09 & 14.25 \\
\hline Date & 23 January & 29 December & 19 February & 17 February & 31 December & 14 January \\
\hline
\end{tabular}

Table 5: Wave height point B

\begin{tabular}{|c|c|c|c|c|c|c|}
\hline \multirow[b]{2}{*}{ Parameters } & \multicolumn{6}{|l|}{ Years } \\
\hline & 2012 & 2013 & 2014 & 2015 & 2016 & 2017 \\
\hline Average & 1.22 & 0.9 & 0.98 & 0.75 & 0.59 & 0.94 \\
\hline Maximum & 2.55 & 3.49 & 2.58 & 3.14 & 1.43 & 2.98 \\
\hline Date & 27 February & 28 December & 12 February & 19 January & 12 February & 10 January \\
\hline
\end{tabular}

Table 6: Wave height point C

\begin{tabular}{lllllll}
\hline & Years & & & & & \\
& - & & & & \\
Parameters & 2012 & 2013 & 2014 & 2015 & 2016 & 0.52 \\
\hline Average & 0.76 & 0.87 & 0.72 & 0.69 & 1.60 \\
Maximum & 2.15 & 2.35 & 1.64 & 1.83 & 1.75 \\
Date & 19 January & 5 January & 18 February & 15 February & 3 January & 19 January \\
\hline
\end{tabular}

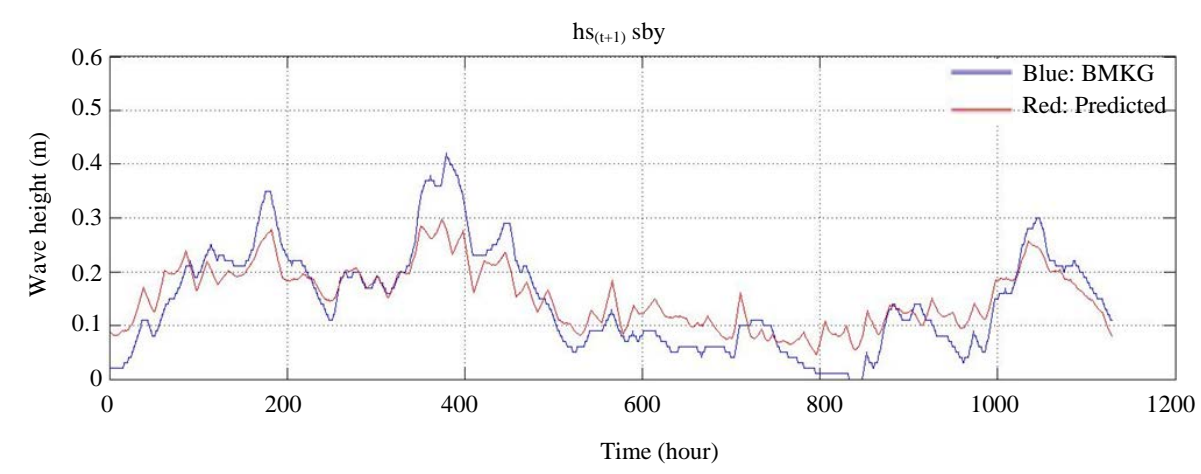

Fig. 3: Predicted Point A using Neural Network 


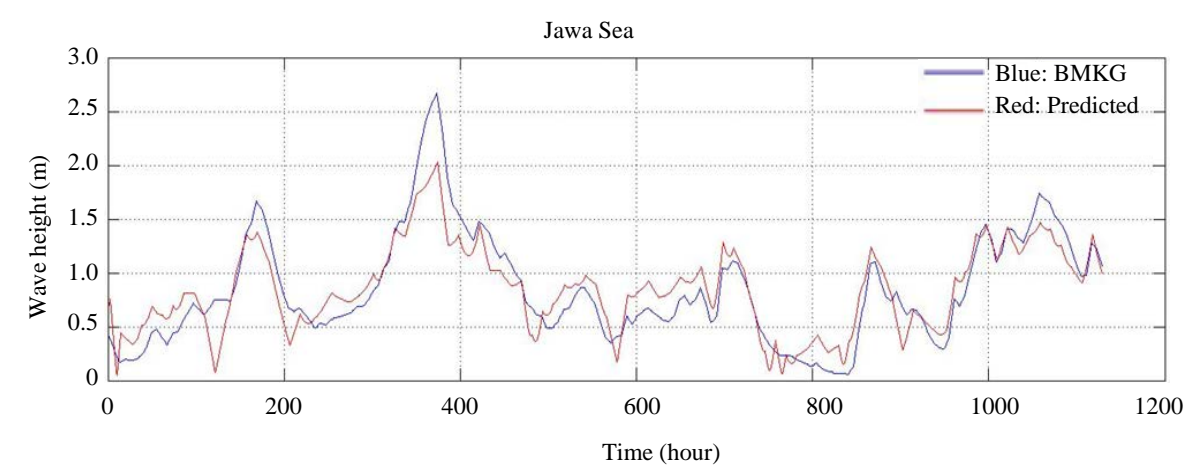

Fig. 4: Predicted Point B using Neural Network

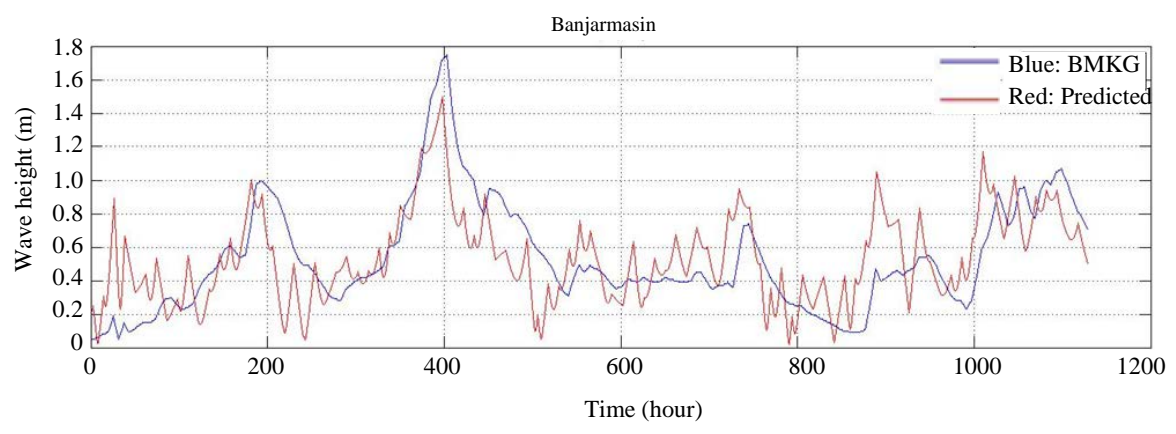

Fig. 5: Predicted Point C using Neural Network

Table 7: Prediction comparison between neural networks and ANFIS Variables $\mathrm{A}$

0.04 ANFIS 0.12

B
0.32

$\mathrm{C}$
0.23
0.38

using ANFIS still need improvement, this is evidenced by the prediction RMSE using ANFIS is still higher than using a neural network. These improvements are more towards fuzzy design, because in ANFIS, fuzzy has a large influence on predictive ability. Table 7 is a prediction comparison between neural networks and ANFIS.

\section{CONCLUTION}

This research can be concluded, that algorithm neural network influenced by architecture network and input-output. Algorithm neural network the best there are at a point namely by rmse 0.04 . In literature review it was mentioned that the less RMSE, the more both based predictions.

\section{REFERENCES}

Dhanistha, W.L., H. Pratikno and Silvianita, 2018a. Neural network for maritime weather prediction. Res. J. Applied Sci., 13: 252-257.

Dhanistha, W.L., R.A. Atmoko, P. Juniarko and R. Akbar, 2017. Prediction of significant wave height using neural network in the java sea (North of Surabaya). Appl. Mech. Mater., 862: 72-77.

Dhanistha, W.L., S. Silvianita and W. Wardhana, 2018b. Wave height prediction based fuzzy logic. Int. J. Civil Eng. Technol., 9: 1611-1616.

Makarynskyy, O., D. Makarynska, M. Kuhn and W.E. Featherstone, 2004. Predicting sea level variations with artificial neural networks at Hillarys Boat Harbour, Western Australia. Estuarine, Coastal Shelf Sci., 61: 351-360.

Paras, M.S., A. Kumar and M. Chandra, 2007. A feature based neural network model for weather forecasting. World Acad. Sci. Eng. Technol., 10: 66-73. 